\title{
CAD-FE modeling and analysis of class II restorations incorporating resin-composite, glass ionomer and glass ceramic materials
}

DOI:

10.1016/j.dental.2017.10.010

\section{Document Version}

Accepted author manuscript

Link to publication record in Manchester Research Explorer

Citation for published version (APA):

Ausiello, P., Ciaramella, S., Martorelli, M., Lanzotti, A., Gloria, A., \& Watts, D. C. (2017). CAD-FE modeling and analysis of class II restorations incorporating resin-composite, glass ionomer and glass ceramic materials. Dental Materials, 33(12), 1456-1465. https://doi.org/10.1016/j.dental.2017.10.010

\section{Published in:}

Dental Materials

\section{Citing this paper}

Please note that where the full-text provided on Manchester Research Explorer is the Author Accepted Manuscript or Proof version this may differ from the final Published version. If citing, it is advised that you check and use the publisher's definitive version.

\section{General rights}

Copyright and moral rights for the publications made accessible in the Research Explorer are retained by the authors and/or other copyright owners and it is a condition of accessing publications that users recognise and abide by the legal requirements associated with these rights.

\section{Takedown policy}

If you believe that this document breaches copyright please refer to the University of Manchester's Takedown Procedures [http://man.ac.uk/04Y6Bo] or contact uml.scholarlycommunications@manchester.ac.uk providing relevant details, so we can investigate your claim.

\section{OPEN ACCESS}




\section{CAD-FE modeling and analysis of Class II restorations incorporating resin-composite, glass ionomer and glass ceramic materials}

Pietro AUSIELLO ${ }^{1}$, Stefano CIARAMELLA $^{2}$, Massimo MARTORELLI $^{2}$, Antonio LANZOTTI ${ }^{2}$, Antonio GLORIA ${ }^{3,}$, , David C WATTS $^{4}$

\footnotetext{
${ }^{1}$ School of Dentistry - University of Naples Federico II, Italy.

2 Department of Industrial Engineering, Fraunhofer JL IDEAS - University of Naples Federico II, Italy.

${ }^{3}$ Institute of Polymers, Composites and Biomaterials - National Research Council of Italy, Naples, Italy.

4 School of Medical Sciences and Photon Science Institute, University of Manchester, United Kingdom.
}

* Corresponding author: angloria@unina.it 
Keywords: CAD; Finite Element Analysis; Class II restorations; Image Analysis; Materials Properties.

\begin{abstract}
Objectives: To investigate the influence of specific resin-composite, glass ceramic and glass ionomer cement (GIC) material combinations in a "multi-layer" technique to replace enamel and dentine in class II mesio-occlusal-distal (MOD) dental restorations using 3D-Finite Element Analysis (FEA).
\end{abstract}

Materials and Methods: Four 3D-FE models (A - D) of teeth, adhesively restored with different filling materials, were created and analyzed in comparison with a 3D model (E) of a sound lower molar. Models A, B \& C had "multilayer" constructions, consisting of three layers: Adhesive, Dentin replacement and Enamel replacement.

Model $A$ : had a low modulus $(8 \mathrm{GPa})$ composite replacing dentin and a higher modulus (12 GPa) composite replacing enamel.

Model $B$ : had a GI cement replacing dentin and a higher modulus (12 GPa) composite replacing enamel.

Model $C$ : had a low modulus (8 GPa) composite replacing dentin and a very high modulus (70 $\mathrm{GPa})$ inlay replacing enamel.

Model $D$ : had a lithium disilicate inlay replacing both dentin and enamel with a luting cement baselayer.

Polymerization shrinkage effects were simulated and a load of $600 \mathrm{~N}$ was applied. All the materials were assumed to behave elastically throughout the entire deformation.

Results: Model A showed the highest stress distribution along all the adhesive interfaces of the shrinking resin-based materials with a critical condition and failure risk marginally and internally. Model D, by contrast, showed a more favorable performance than either of the multilayer groups (A-C). Stress and displacement plots showed an elastic response similar to that obtained for the sound tooth model. Model B and Model C performed according to their bilayer material properties. The use of a non-shrink dentin component simulating a GIC clearly affected the shrinkage stress at the basis of the Model B; while the bulk resin composite having a $12 \mathrm{GPa}$ Young's Modulus and linear polymerization shrinkage of $1 \%$ strongly influenced the biomechanical response in the buccolingual direction. 
Significance. Direct resin-based composite materials applied in multilayer techniques to large class II cavities, with or without shrinking dentin layers, produced adverse FEA stress distributions and displacements. An indirect lithium disilicate inlay used to replace lost dentine and enamel in posterior restored teeth generated lower stress levels, within the limits of the elastic FEA model.

\section{Introduction}

Resin-based composites have physical and aesthetic properties which are generally suitable for class II restorations for class I and class II adhesive restorations. [1-3]. However, when the cavity is extensive after caries removal, different direct or indirect materials combinations and techniques may be required [4]. Resin-composites directly placed in dental cavities may still present appreciable dimensional changes during photocuring due to polymerization shrinkage of the dimethacrylate monomers [5]. Stress is physically associated with this phenomenon and occurs depending on resin composite characteristics [6]. Resin-composites show a volumetric shrinkage from $1 \%$ up to $4.8 \%$ depending on several chemical and physical factors [5]. The internal stress developed during polymerization is related to the Young's modulus of the material [6]. When class I and mainly class II cavities are adhesively restored, stresses following the shrinkage process can act negatively, internally and marginally to produce a failure risk [7]. These phenomena have been investigated experimentally [8-11] and by means of finite element analysis [12-18].

Longevity of posterior restorations is limited by many factors - especially the materials, the patient and the dentist. [19]. Hypersensitivity, staining, secondary caries by bacterial penetration under cyclic loading and cusp displacement, with possible crack and dental fracture development at surroundings walls, are documented clinical and microscopic consequences. Shrinkage phenomena are influenced by the material composition - especially volume percent of inorganic filler, irradiation modes, quality of polymerization, degree of conversion and boundary conditions, [20]. Bulk fill composites may partially overcome some of these limits [21] as an alternative to a careful layering technique [22]. Light irradiation modes require careful consideration [23]. Also material combinations using a base layer of $0.5-1 \mathrm{~mm}$ on the cavity floor may improve the marginal integrity of adhesive restoration [23]. In these cases materials with lower rigidity and minimal or zero shrinkage are indicated.

Even though in the literature there are some studies reporting combinations of materials in the form of multilayer systems, the current research was focused on a further analysis on a specific resincomposite, glass ceramic and glass ionomer cement (GIC) material combinations in a "multi-layer" 
technique to replace enamel and dentine in class II mesio-occlusal-distal (MOD) dental restorations using 3D-Finite Element Analysis (FEA).

Specifically, the aim of the present investigation was to examine specific resin and glass ceramic materials in various combinations to evaluate the stresses and displacements in class II restorations by means of a linear elastic 3D finite element analysis (FEA) to characterize strategies for dentin and enamel replacement.

\section{Materials and methods}

A 3D computer-aided design (CAD) model of the sound tooth was built-up starting from Microcomputed tomography (micro-CT) scan images [16] to generate the shapes of dentin, pulp and enamel. From a sound tooth CAD model, class II MOD preparations were introduced and restored tooth models were created. Finally, 3D finite element (FE) models were built-up and finite element analysis (FEA) was performed to investigate the influence of different resin-based material combinations in a multilayer technique. When Glass Ionomer Cement (GIC) is used for the base layer, sometimes this is referred to as a sandwich technique. But more general terms are bilayer or multilayer.

\section{Generation of tooth solid model}

The sound tooth was digitized with a high-resolution micro-CT scanner system (1072, SkyScan, Belgium). A total of 471 slices were collected using an image resolution 1024 x 1024 pixels, a voltage at $110 \mathrm{kV}$ and a voxel dimension of $19.47 \mu \mathrm{m}$. Isosurfaces were detected by using the "KMeans" clustering algorithm that operates by grouping image pixels, defined with their gray scale, into K groups/clusters. A constant pixel value was associated with each cluster. By using this classification, for the i-th slice, logical matrices (pixel mask) of pixels were introduced: the value of the $\mathrm{t}$-th pixel was equal to " 1 " if it belonged to the k-th cluster, otherwise it was assumed equal to “0”. Enamel and dentin regions were considered as the two clusters. Taking into account the marching-cube algorithm, tessellated surfaces were created. Using such procedure, it was possible to connect pixels having the same value on different slices. With regard to the surface tessellation, the "isosurface" function available in Matlab ${ }^{\circledR}$ was used, SolidWorks ${ }^{\circledR}$ CAD software was employed to create 3D volumes. Starting from the surface tessellation the sound and restored tooth models were created in Evolve $2015^{\odot}$ (solidThinking Inc, Altair Company) software. 
The tooth model was placed in a coordinate system, where the X-and Y-axes were chosen for the buccolingual direction and mesiodistal direction, respectively, and the Z-axis was oriented upwards. The trim tool was used to remove a part of the two solids (enamel and dentin). A solid model with margin angle of the cavity restoration $\alpha=95^{\circ}$ was created (Fig. 1). Flat floor and sharp internal line angles characterized the cavity design. For the crown, $10.5 \mathrm{~mm}$ and $12.4 \mathrm{~mm}$ were selected as the buccolingual and mesiodistal diameters, respectively, whereas $7.8 \mathrm{~mm}$ was assigned as the cervicoocclusal length. To obtain the final crown, the base of the model was established in the cervical area.

\section{Numerical simulation}

The solid models of the sound and restored tooth were imported into the HyperWork ${ }^{\circledR}$ 14.0 (Altair Engineering Inc) environment, using the IGES format.

Three models of a restored tooth with a multilayer construction were created and investigated using different material combinations (Table 1), as follows [24-26]:

Model $A$ : (i) Adhesive layer: $10 \mu \mathrm{m}$ thick with $1 \%$ linear shrinkage and $4 \mathrm{GPa}$ Young's modulus. (ii) Dentin replacement: flowable resin-composite with $1 \%$ linear shrinkage and 8 GPa Young's modulus; (iii) Enamel replacement: Resin-composite with $1 \%$ linear shrinkage and 12 GPa Young's modulus.

Model B: (i) Adhesive layer (only under enamel-replacing material): $10 \mu \mathrm{m}$ thick with $1 \%$ linear shrinkage and 4 GPa Young's modulus. (ii) Dentin replacement: Glass-Ionomer cement (GIC): zero-shrinkage and $8 \mathrm{GPa}$ Young's modulus; (iii) Enamel replacement: resin-composite with $1 \%$ linear shrinkage and $12 \mathrm{GPa}$ Young's modulus.

Model $C$ : (i) Luting cement layer (only around the ceramic inlay): $10 \mu \mathrm{m}$ thick luting resin cement with 1\% linear shrinkage and $6 \mathrm{GPa}$ Young's modulus (ii) Dentin replacement: flowable resincomposite with $1 \%$ linear shrinkage and 8 GPa Young's modulus; (iii) Enamel replacement: , lithium disilicate inlay with $70 \mathrm{GPa}$ Young's modulus.

For the thicknesses of the "dentin replacing material", $0.4 \mathrm{~mm}$ and $1.2 \mathrm{~mm}$ were assigned for the center of the tooth and the mesial and distal floor boxes, respectively, whereas $1.4 \mathrm{~mm}$ was assigned for the mid-thickness of the enamel-replacing material.

Model $D$ : (i) Luting cement layer (only beneath the ceramic inlay): $70 \mu \mathrm{m}$ thick and $6 \mathrm{GPa}$ Young's Modulus; (ii) lithium disilicate inlay with $70 \mathrm{GPa}$ Young's modulus.

The maximum normal stress criterion was considered to analyze the results. The numerical results were compared with the sound tooth response (Model E). Thus, five FE models were analyzed. For each model, the number of elements, nodes and aspect ratio were reported (Table 2). 
In the tooth models each tissue was defined in terms of mechanical properties. With regard to enamel, a Young's modulus and Poisson's ratio of $80 \mathrm{GPa}$ and 0.30 were used, respectively. 18 GPa and 0.23 were used for dentin. The Young's moduli and Poisson's ratios used for the different restorative materials are listed in Table 1. Concerning the food bolus, a Young's modulus (10 MPa) and Poisson's ratio (0.3) were assigned.

A 3D mesh was created and each tooth model was divided into 3D solid CTETRA elements with four grid points. To increase the structural relevance of the model, special technical improvements were made in the FE model generation.

All the analyses were focused on load during the closing phase of the chewing cycle. The variability of chewing function was taken into account being dependent on the contact between food bolus (Fig. 2) and tooth surface. Regarding the occlusal surfaces, slide-type contact elements were used between tooth surface and food, whereas freeze-type contact elements were used for the remaining interfaces.

With regard to the restored tooth, for each model the combined effects of polymerization shrinkage and occlusal load were analyzed in terms of stress and displacement distributions.

Shell elements were used for modelling the resin bonding and luting resin cement layers. The assigned magnitudes of linear shrinkage (\%) are reported in Table 1 . To simulate the effect of polymerization shrinkage for the adhesive layers and resin composite materials, the thermal expansion approach was used. A linear thermal expansion coefficient of 0.01 was assumed. The volume coefficient of thermal expansion was equal to 0.03 as the material was considered isotropic. By assigning a one-degree drop in temperature of the adhesive layers and composite volumes shrinkage and stress were generated at the tooth-restoration interface. The combined effect of this shrinkage and an occlusal static load of $600 \mathrm{~N}[16,17]$ - vertically applied and uniformly distributed on the surface - was analyzed. Nodal displacements on the lower model surfaces were constrained in all directions. A linear static analysis was performed.

\section{Results}

In Figures 3 and 4 contour plots of principal stresses are reported. Further quantitative results were observed from defined inspection paths. Paths 1 and 2 were buccolingually directed and located near the enamel-dentin interface in the mesial floor boxes and in the center of the tooth, respectively (Figs. 5-6). Path 3 was mesiodistally directed and located near the enamel-dentin interface and the restored-natural tooth interface, on the lingual side (Fig. 7). Path 4 was mesiodistally directed and 
located on the cavity floor (Fig. 8). Path 5 followed the profile of the buccal wall from the base of the tooth to the cusp (Fig. 9).

First principal stresses were plotted along paths 1-4 (Figs 5-8) and displacements in the buccal direction were reported along path 5 (Fig. 9).

For models A and B high stresses were found in the cavity region. The response of model D was similar to that of the sound tooth (model E) and model $\mathrm{C}$ showed intermediate behavior (Figs 5, 6). With regard to Fig. 7, for models A and B, the highest stress values were obtained in the center region on the enamel-dentin interface. Furthermore, in this plot, the response of model D was similar to that of the sound tooth and model $\mathrm{C}$ showed intermediate behavior.

\section{Discussion}

Human teeth have a complex structure based on material combinations with complementary mechanical properties [27, 28]. It is well known that stress distributions are related to the stiffness, which depends upon the Young's Modulus (an intrinsic mechanical property of the material) and shape and size [26]. Sound teeth comprise two main parts: crown and root, formed from enamel and dentin. Cementum is a residual tissue in a thin layer around root dentine. The anatomical and histological structures of posterior teeth confer resistance to fracture during mastication and facilitate more uniform stress distributions [30]. Enamel has a Young's modulus ( $80 \mathrm{GPa}$ ) which is higher than that of dentin (18 GPa).

The mechanical behavior of premolars and molars, adhesively restored using resin-based composites, has been investigated under occlusal loading either under laboratory conditions [29, 31 33] or by means of finite element analysis of sound (restored) teeth [13, 18, 34, 35, 37, 38]. Dental decay severely reduces the mechanical strength of posterior teeth under food mastication. So, the restorative materials must create a strong adhesive bridge between the opposing walls of the restored cavity $[16,17]$. The aim is to replace the properties and function of the lost tissues as closely as possible, limiting debonding, marginal leakage and fracture [31, 32]. Morphology, function and aesthetics must also be replaced. In the present investigation, as previously [16-17], the biomechanical response has been simulated, according to the mechanical behavior of resin composite, glass ceramic and ionomer materials used to adhesively fill II MOD dental cavities in a posterior tooth using multilayer techniques, where shrinking and non-shrinking materials have been used. Results have shown significantly different outcomes with the varied materials. The more adverse outcomes were found with models A and B. In model A, full adhesive restoration, with resin-based shrinking materials, displayed high stresses and thus a high risk of marginal damage, as 
seen in inspection Paths 1 and 2 - bucco-lingually along the enamel-dentine junction (Fig. 5). In this case, a combination of resin-based materials: adhesive $(\mathrm{E}=4 \mathrm{GPa})$ plus a flowable composite $(\mathrm{E}=8 \mathrm{GPa})$ and a bulk composite $(\mathrm{E}=12 \mathrm{GPa})$, was used. Even though resin-composites with a Young's modulus up to $25 \mathrm{GPa}$ are available on the market and are still much lower than $80 \mathrm{GPa}$, in the current research, as an example, a material having a modulus of $12 \mathrm{GPa}$ was considered to assess the combined effect of the Young's modulus and the shrinkage. Resin composite thickness and its Young's modulus strongly influence stress redistribution at adhesive interfaces particularly stress relief into the cusps [7, 13]. As internal stresses have been indicated as a prime failure mechanism of the restoration, a good restoration can minimize them [35]. So, it is of fundamental importance to evaluate how to create better conditions to mechanically resist occlusal loading. In the study by Hojjatie and Anusavice [35] an analysis by von Mises stress simulation was conducted. This showed stresses were dependent on the higher elastic modulus of the restorative material and on the cavity shape. Resin composite onlays showed the best overall performance in minimizing internal stresses. These findings have been partly confirmed in a recent investigation [16], where it was suggested that in Class II MOD inlays, $95^{\circ}$ cavity-margin-angles under a $600 \mathrm{~N}$ load gave greater relief of principal stresses. Another investigation [38] also showed how in large class II MOD cavities an indirect pre-cured resin composite was superior than direct use of resin bulk composite materials in reducing shrinkage stress effects. The present investigation confirms these interpretations [15, 35]. Anyway, our focus was on resin, glass-ceramic and ionomer material combinations applied in a multilayer technique. Our 3D finite element investigation shows that an indirect composite material $(\mathrm{E}=12 \mathrm{GPa})$ adhesively bonded by a resin-based $70 \mu \mathrm{m}$ shrinking cement $(\mathrm{E}=6 \mathrm{GPa})$ within a class II MOD cavity was similar to sound natural tooth behavior. These findings were, in part, previously investigated in class II MOD adhesive restorations where the potentially adverse effects were shown of $1 \%$ linear polymerization shrinkage of a bulk fill restoration on its marginal adaptation to cavity walls [17]. In this context, where composite has been used to replace both enamel and dentin, shrinkage stress has evidently greater consequence than occlusal loading stress and displacements alone. This confirms the findings of previous modeling of class II MOD adhesive restorations [15].

With regard to the first principal stress distribution at the center of the MOD II cavity restoration (Path 2, Fig. 6), corresponding to the isthmus of the cavity, at the enamel-material interfaces stress values were slightly higher than those reported for model A and model B in Fig. 4 (i.e., ranging from -10 MPa to $+140 \mathrm{MPa}$ and from -30 MPa to $+115 \mathrm{MPa}$, respectively), as Path 2 was located closer to the stressed areas. At the enamel interface model $\mathrm{C}$ also showed a higher stress level than 
that reported in Fig. 5, while model D continued to provide the best pattern in terms of stress distribution as well as the sound tooth in Fig. 5.

In model B (Fig. 5), the presence of a layer of non-shrink GIC base material did not create an effective stress-absorbing layer. This is in disaccord with a previous investigation [27] where a possible advantage of a liner material was suggested. In model B, the GIC layer - $1.2 \mathrm{~mm}$ on the box floor and of $0.4 \mathrm{~mm}$ on the isthmus floor - did not significantly modify the pattern of stresses arising from polymerization of a $12 \mathrm{GPa}$ Young's modulus resin composite, enamel replacing material. According to inspection path 3 (Fig. 7), stresses were not present along the cavity floor.

As reported in Path 3 (Fig. 7), as a result of shrinkage effect in conjunction with load application, stresses were distributed in the overall restored cavities, even if the obtained values were everywhere lower than those in Path 1 and Path 2 analyses. It is worth noting that along the mesiodistal direction the most stressed interfaces were attained for model A and model B. Specifically, in the investigated range of distance, stress varied from - $30 \mathrm{MPa}$ to $+60 \mathrm{MPa}$. As a consequence of the only shrinking effect of the dentine replacing material, model $\mathrm{C}$ was less stressed than model A and model B. Furthermore, looking at the central part of Path 3, a mechanical behavior closer to those of model D and sound tooth was achieved.

Comparing models $\mathrm{A}$ and $\mathrm{B}$, their behavior was not equivalent in respect of shrinkage stress magnitudes. Model A stressed more the full tooth-restoration. From Fig. 9, where displacements were investigated, the curves appear comparable. This indicates that the effect of occlusal loading played the same role depending on the identical elastic property of the resin-based bulk filling material employed in models $\mathrm{A}$ and $\mathrm{B}(\mathrm{E}=12 \mathrm{GPa})$.

Furthermore, model A was totally stressed along the mesiodistal direction, where a shrinking material was considered as dentine replacing material, even if lower stress values were obtained if compared to the results reported in Path 1, 2 and 3. However, in this direction model B, where a non-shrinking material was employed as liner on the floor (i.e., glass ionomer), performed better.

Anyway, a more marked shrinkage effect was well evident for model A and model B by increasing the distance from the bottom to the top of the restored teeth (Figure 9).

Concerning model $\mathrm{C}$ and model D, where non-shrinking materials were used to replace the enamel, a mechanical behavior close to the sound tooth was found. Taking into account Path 5 , both model $\mathrm{C}$ and model D showed a mechanical performance similar to that of the sound tooth. 


\section{Conclusions}

Taking into account the analyzed material combinations, the FEA linear analysis, assuming isotropic elastic material behavior, suggests that:

1. The use of direct resin-based shrinking composite and ionomer materials in a multilayer technique in large class II cavities with deep dentine and enamel loss can be considered a limited clinical option because of adverse stress distributions and displacements.

2. In the reported cases the indirect lithium disilicate ceramic material is indicated to better replace the lost dentine and enamel in posterior restored teeth.

\section{References}

1. Yazici AR, Ustunkol I, Ozgunaltay G, Dayangac B. Three-year clinical evaluation of different restorative resins in class I restorations. Oper Dent. 2014 May-Jun;39(3):248-55. doi: 10.2341/13-221-C.

2. Quality and Survival of Direct Light-Activated Composite Resin Restorations in Posterior Teeth: A 5- to 20-Year Retrospective Longitudinal Study. Borgia E, Baron R, Borgia JL. J Prosthodont. 2017 May 17. doi: 10.1111/jopr.12630.

3. Sideridou ID, Karabela MM, Vouvoudi ECh. Physical properties of current dental nanohybrid and nano fill light-cured resin composites. Dent Mater. 2011; 27:598-607.

4. da Veiga AM, Cunha AC, Ferreira DM, da Silva Fidalgo TK, Chianca TK, Reis KR, Maia LC. Longevity of direct and indirect resin composite restorations in permanent posterior teeth: A systematic review and meta-analysis. J Dent. 2016 Nov;54:1-12

5. Davidson CL, Feilzer AJ. Polymerization shrinkage and polymerization shrinkage stress in polymerbased restoratives. J Dent 1997; 25:435-44

6. Al Sunbul H, Silikas N, Watts DC .Polymerization shrinkage kinetics and shrinkage-stress in dental resin-composites. Dent Mater. 2016; 32:998-100

7. Versluis A, Tantbirojn B, Pintado MR, DeLong R, Douglas WH. 2004. Residual shrinkage stress distributions in molars after composite restoration. Dent Mater. 2014; 20: 554-564

8. Herzl Chai, Brian R. Lawn. Fracture resistance of molar teeth with mesial-occlusal-distal (MOD) restorations. Dental Materials Available online 20 May 2017

9. Boaro LC, Brandt WC, Meira JB, Rodrigues FP, Palin WM, Braga RR. Experimental and FE displacement and polymerization stress of bonded restorations as a function of the C-Factor, volume and substrate stiffness. J Dent. 2014; 42:140-148. 
10. Braga RR, Koplin C, Yamamoto T, Tyler K, Ferracane JL, Swain MV. Composite polymerization stress as a function of specimen configuration assessed by crack analysis and finite element analysis. Dent Mater. 2013; 29:1026-33

11. Yamada Y, Tsubota Y, Fukushima S. Effect of restoration method on fracture resistance of endodontically treated maxillary premolars. Int J Prosthodont. 2004 Jan-Feb; 17(1):94-8.

12. Williams KR, Edmundson JT, Rees JS. Finite element Stress analysis of restored teeth. Dent Mater. 1987 Aug;3(4):200-206.

13. Ausiello P, Apicella A, Davidson CL. Effect of adhesive layer properties on stress distribution in composite restorations--a 3D finite element analysis. Dent Mater. 2002; 18:295-303.

14. Iqbal Musani and AR Prabhakar. Biomechanical Stress Analysis of Mandibular First Permanent Molar Restored with Amalgam and Composite Resin: A Computerized Finite Element Study Int J Clin Pediatr Dent. 2010 Jan-Apr; 3(1): 5-14.

15. Dejak B, Mlotkowski A. A comparison of stresses in molar teeth restored with inlays and direct restorations, including polymerization shrinkage of composite resin and tooth loading during mastication. Dent Mater. 2015; 31:77-87.

16. Ausiello P, Ciaramella S,Garcia-Godoy F, Gloria A, Lanzotti A, Maietta S, Martorelli M. The effect of cavity-margin-angles and bolus stiffness on the mechanical behavior of indirect resin composite class II restorations. Dent Mater 2016;24:109-5641

17. Ausiello P, Ciaramella S, Fabianelli A, Gloria A, Martorelli M, Lanzotti A, Watts D C. Mechanical behavior of bulk direct composite versus block composite and lithium disilicate indirect restorations by CAD-FEM modeling. Dent Mater 2017; 33:690-701

18. Ausiello P, Rengo S, Davidson CL, Watts DC. 2004. Stress distributions in adhesively cemented ceramic and resin-composite Class II inlay restorations: a 3D-FEA study. Dent Mater. 2004; 20:862- 872

19. Hickel R, Manhart J. Longevity of restorations in posterior teeth and reasons for failure. J Adhes Dent. 2001 Spring;3(1):45-64

20. Takahashi H, Finger WJ, Wegner K, Utterodt A, Komatsu M, Wöstmann B, Balkenhol M Factors influencing marginal cavity adaptation of nanofiller containing resin composite restorations. Dent Mater. 2010 Dec;26(12):1166-75.

21. L.C. Boaro, F. Gonçalves, T.C. Guimarães, J.L. Ferracane, C.S. Pfeifer, R.R. Braga. Sorption, solubility, shrinkage and mechanical properties of low-shrinkage commercial resin composites. Dent Mater 2013; 29: 398-404

22. Fabianelli A, Sgarra A, Goracci C, Cantoro A, Pollington S, Ferrari M. Microleakage in class II restorations: open vs closed centripetal build-up technique. Oper Dent. 2010 MayJun;35(3):308-13. doi: 10.2341/09-128-L. Erratum in: Oper Dent. 2010 Jul-Aug;35(4):487.

23. Yoshikawa T, Burrow MF, Tagami J. A light curing method for improving marginal sealing and cavity wall adaptation of resin composite restorations. Dent Mater. 2001 Jul;17(4):359-66

24. Labella R, Lambrechts P, Van Meerbeek B, Vanherle G. Polymerization shrinkage and elasticity of flowable composites and filled adhesives. Dent Mater. 1999; 15:128-37.

25. Attar N, Tam LE, McComb D. Flow, strength, stiffness and radiopacity of flowable resin composites. J Can Dent Assoc. 2003 Sep;69(8):516-21.

26. Ferracane JL. Resin composite-state of the art. Dent Mater. 2011 Jan;27(1):29-38. 
27. Aggarwal V, Singla M, Yadav S, Yadav H. Effect of flowable composite liner and glass ionomer liner on class II gingival marginal adaptation of direct composite restorations with different bonding strategies. J Dent. 2014 May;42(5):619-25. doi: 10.1016/j.jdent.2014.02.016. Epub 2014 Mar 11

28. Musani I, Prabhakar AR. Biomechanical Stress Analysis of Mandibular First Permanent Molar; Restored with Amalgam and Composite Resin: A Computerized Finite Element Study. Int J Clin Pediatr Dent. 2010 Jan-Apr;3(1):5-14.

29. Zhang H, Cui JW, Lu XL, Wang MQ Finite element analysis on tooth and periodontal stress under simulated occlusal loads. J Oral Rehabil. 2017 Jul; 44(7):526-536. doi: 10.1111/joor.12512. Epub 2017 Apr 27.

30. Ausiello P, Apicella A, Davidson CL, Rengo S. 3D-finite element analyses of cusp movements in a human upper premolar, restored with adhesive resin-based composites J Biomech. 2001 Oct;34(10):1269-77.

31. Ausiello P, De Gee AJ, Rengo S, Davidson CL Fracture resistance of endodontically-treated premolars adhesively restored. Am J Dent. 1997 Oct;10(5):237-41.

32. Ausiello P, Davidson CL, Cascone P, DeGee AJ, Rengo S Debonding of adhesively restored deep Class II MOD restorations after functional loading. Am J Dent. 1999 Apr;12(2):84-8.

33. Arola D, Galles LA, Sarubin MF.A comparison of the mechanical behavior of posterior teeth with amalgam and composite MOD restorations. J Dent. 2001 Jan;29(1):63-73

34. Hojjatie B, Anusavice KJ. Three-dimensional finite element analysis of glass-ceramic dental crowns. J Biomech. 1990;23(11):1157-66.

35. Jiang W, Bo H, Yongchun G, LongXing N Stress distribution in molars restored with inlays or onlays with or without endodontic treatment: a three-dimensional finite element analysis. J Prosthet Dent. 2010 Jan;103(1):6-12.

36. Ausiello P, Franciosa P, Martorelli M, Watts DC. Numerical fatigue 3D-FE modeling of indirect composite-restored posterior teeth. Dent Mater. 2011 May;27(5):423-30.

37. Fennis WM, Kuijs RH, Barink M, Kreulen CM, Verdonschot N, Creugers NH. Can internal stresses explain the fracture resistance of cusp-replacing composite restorations? Eur J Oral Sci. 2005 Oct;113(5):443-8.

38. Ausiello P, Ciaramella S, Garcia-Godoy F, Martorelli M, Sorrentino R, Gloria A. Stress distribution of bulk-fill resin composite in calss II restorations. Am J Dent. 2017 August; 30(4): 227-232. 


\section{Figures and figure captions}

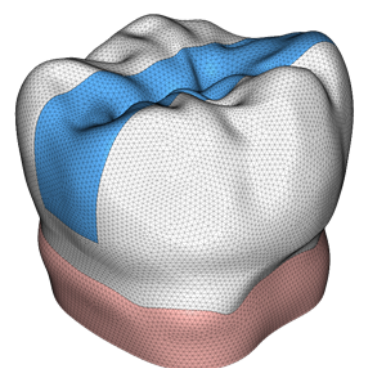

a)

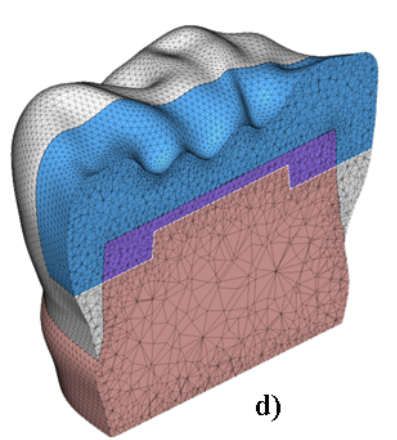

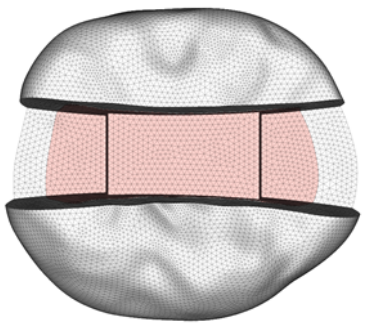

b)

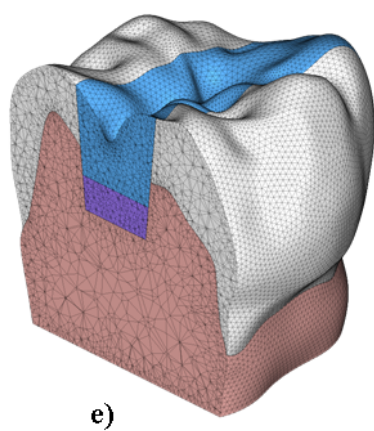

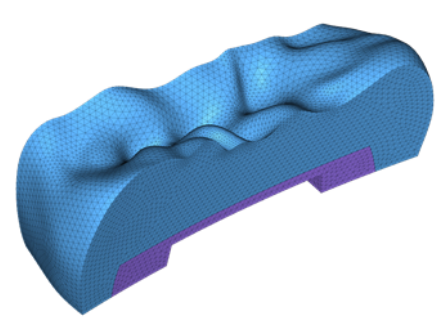

c)

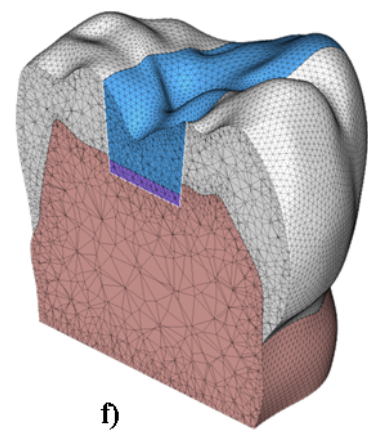

Figure 1 - 3D FE model of tooth. a) Restored tooth; b) Cavity; c) bilayer filling materials; f) Mesiodistal cut section at the center of the tooth; e) Bucco-lingual cut section corresponding to mesial floor boxes; f) Bucco-lingual cut section at the center of the tooth 


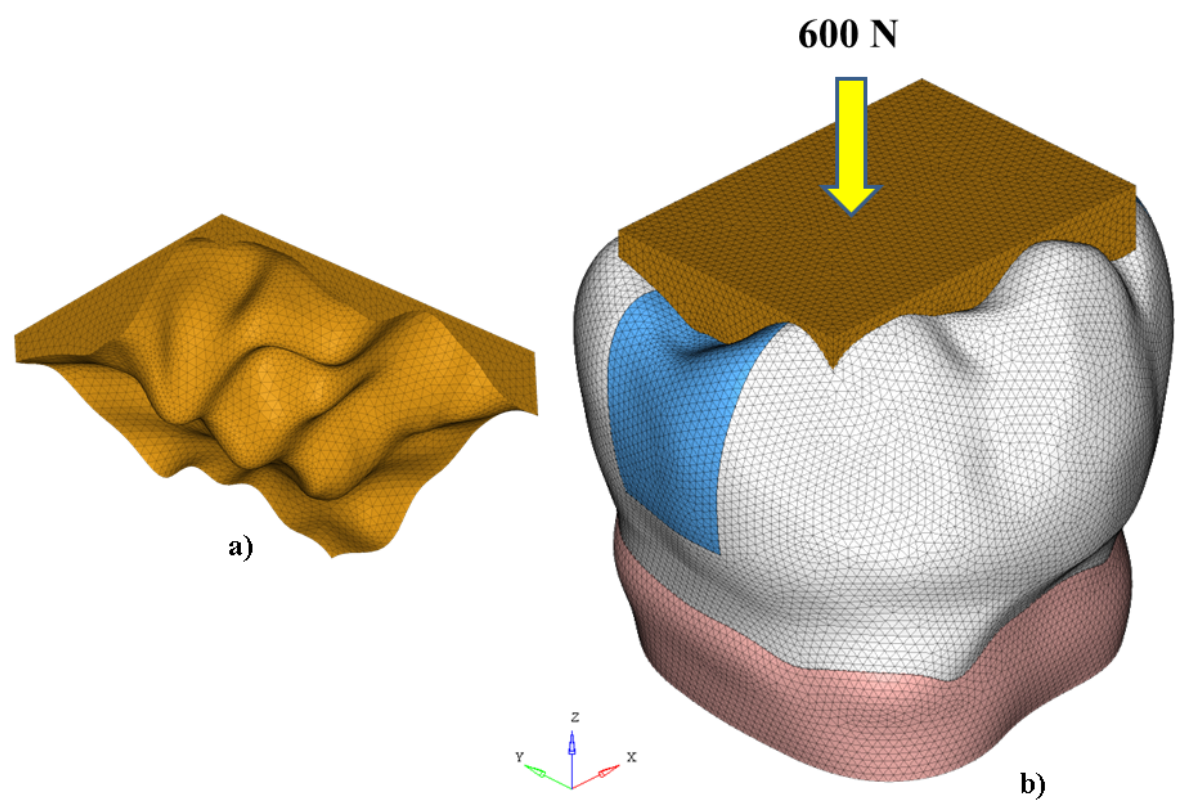

Figure 2 - Food modelling and occlusal load. a) Bolus on the occlusal surfaces; b) Overall FE model

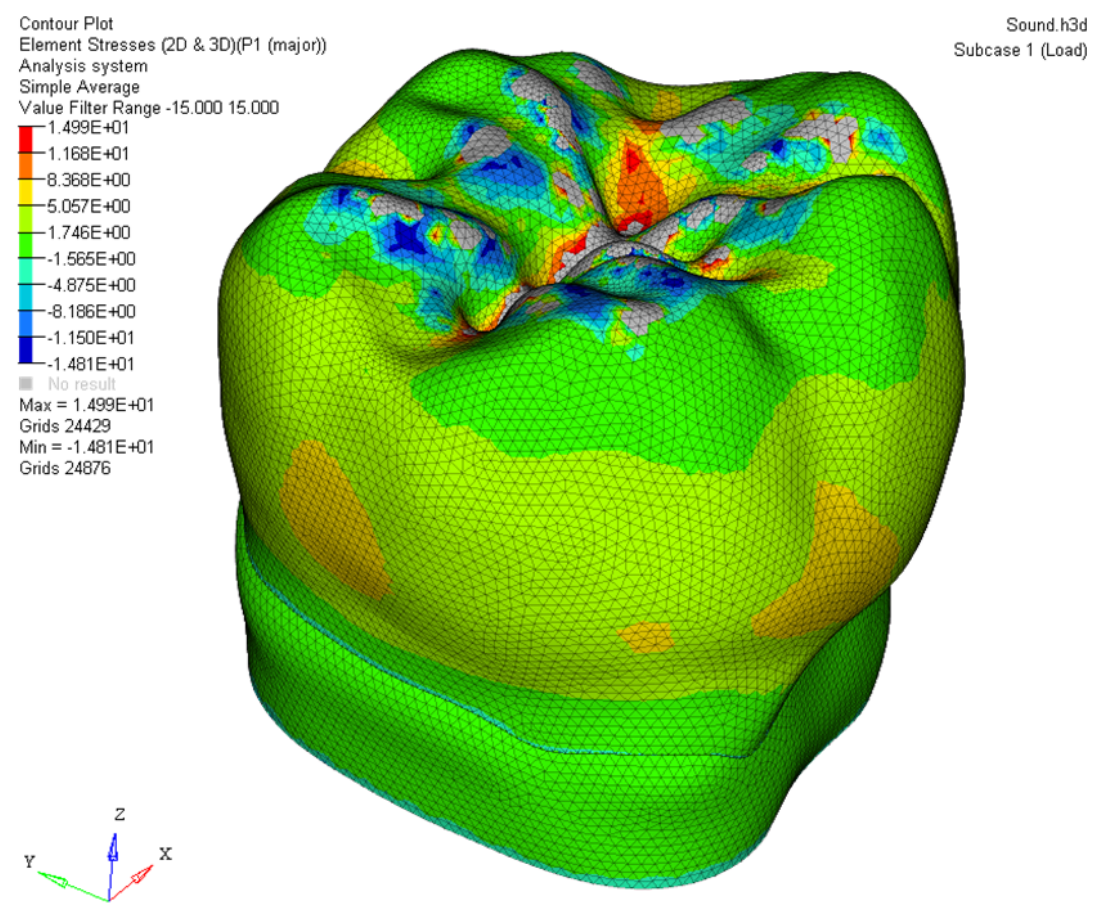

Figure 3 - First principal stress distribution in the sound tooth 


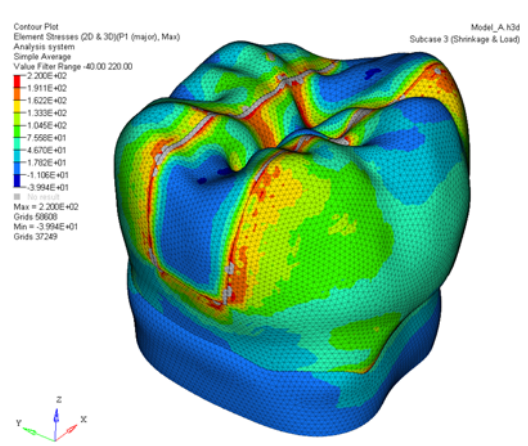

(a)

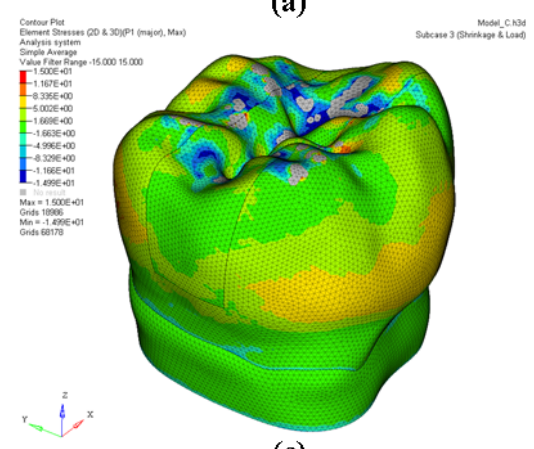

(c)

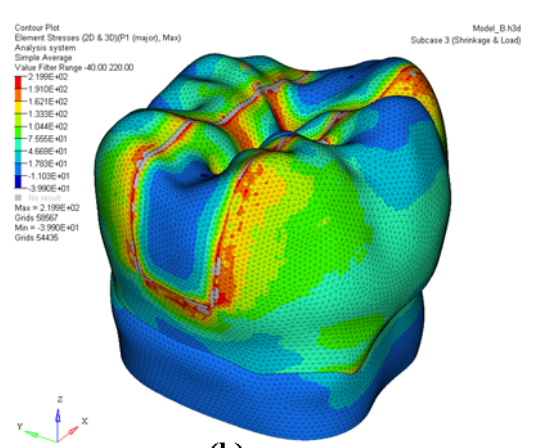

(b)

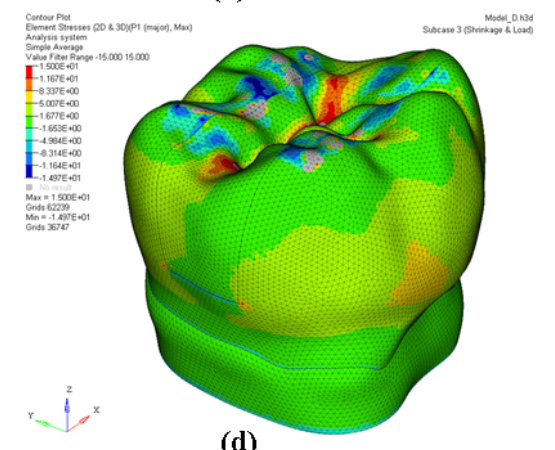

(d)

Figure 4 - 3D Stress magnitudes in restored tooth models A-D

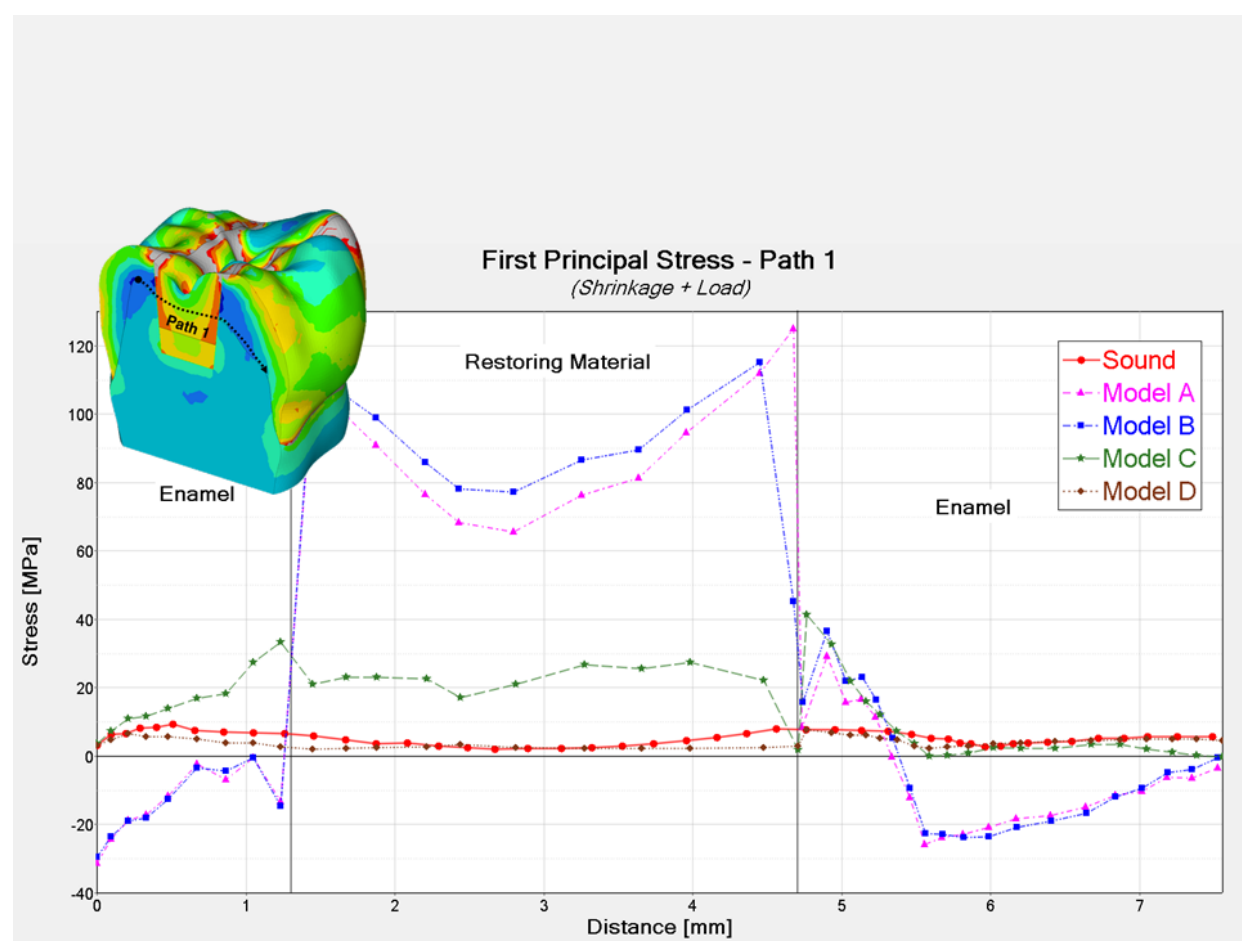

Figure 5 - First principal stress distributions (MPa) along inspection path 1 


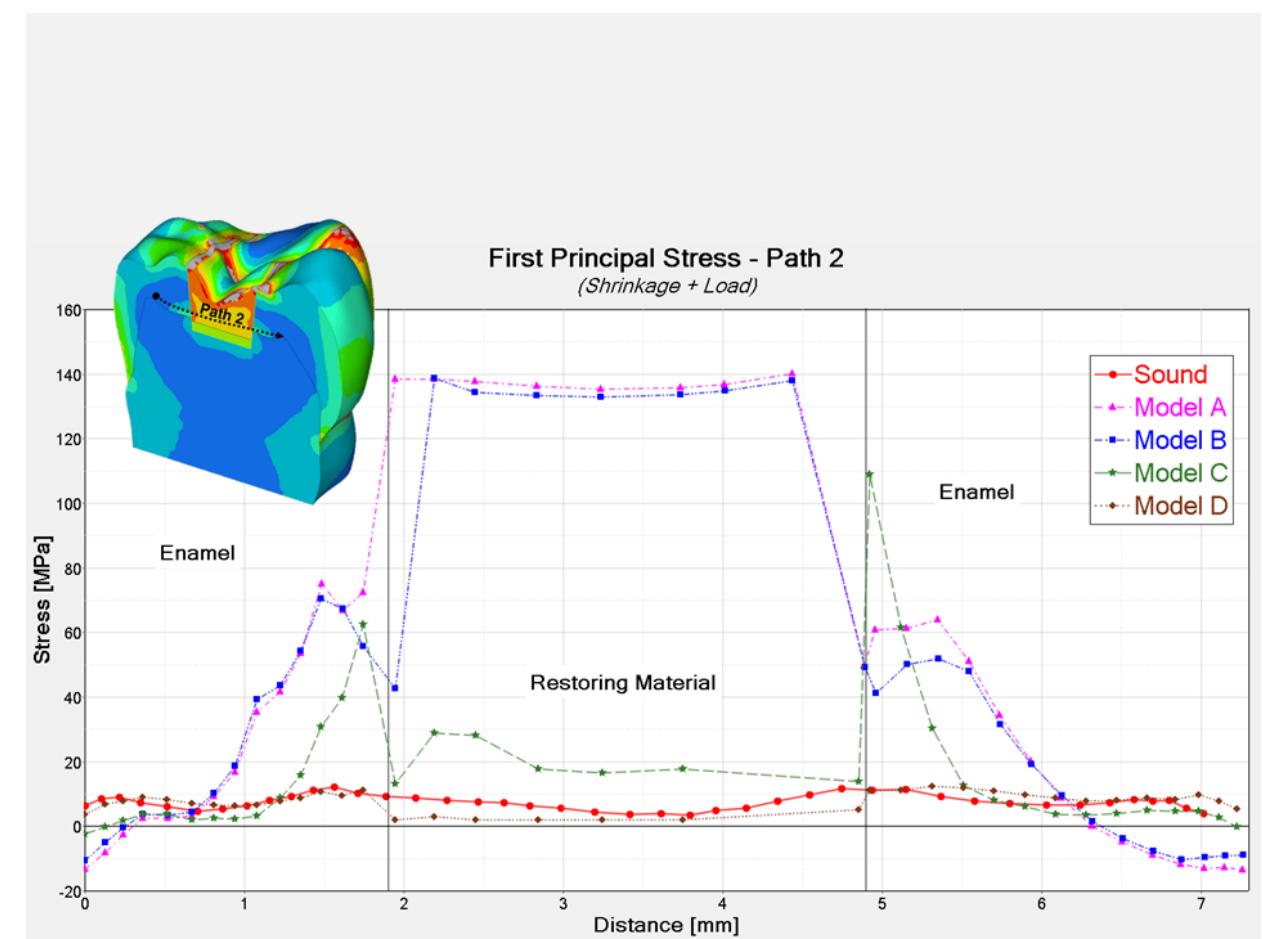

Figure 6 - First principal stress distributions (MPa) along inspection path 2

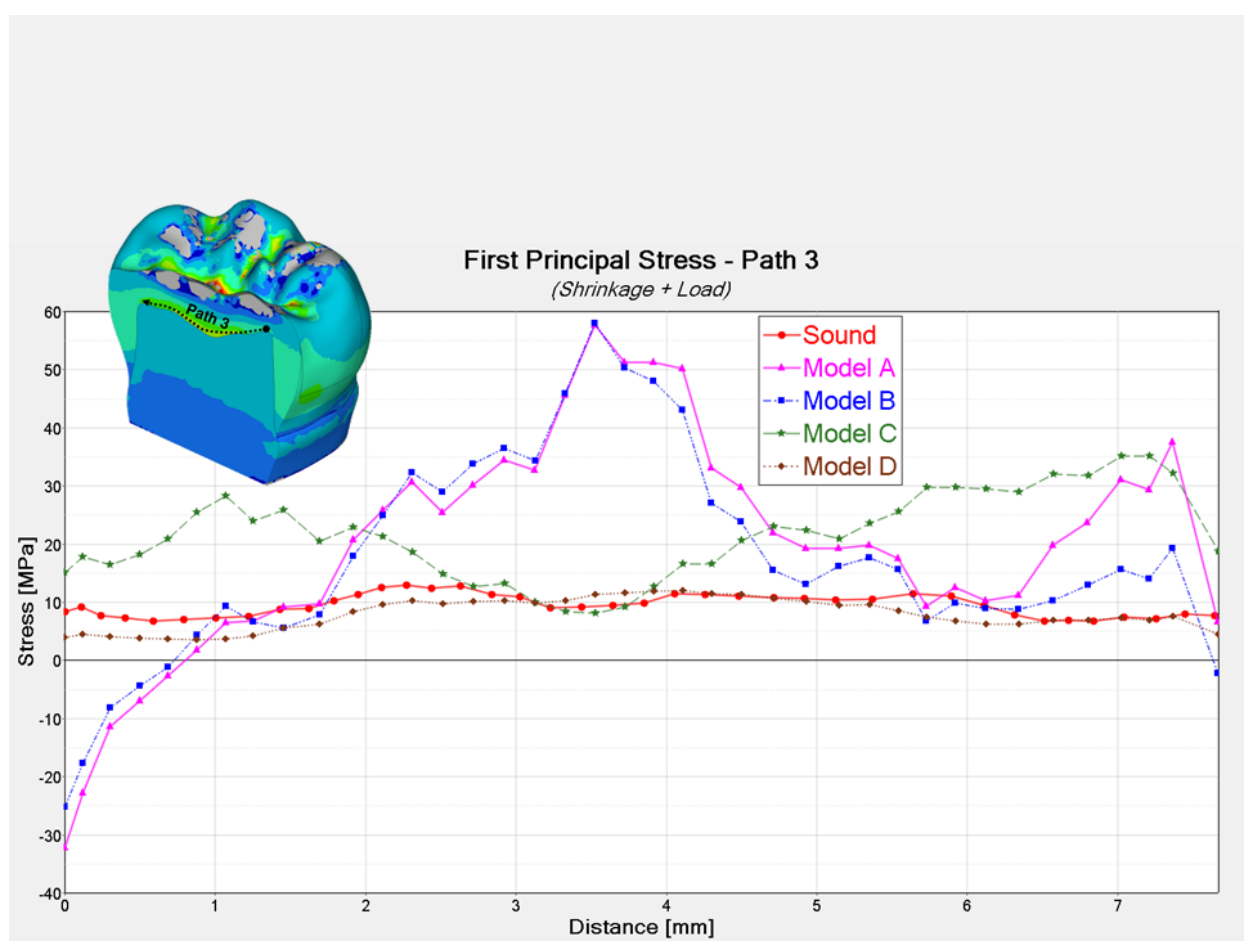

Figure 7 - First principal stress distributions (MPa) along inspection path 3 


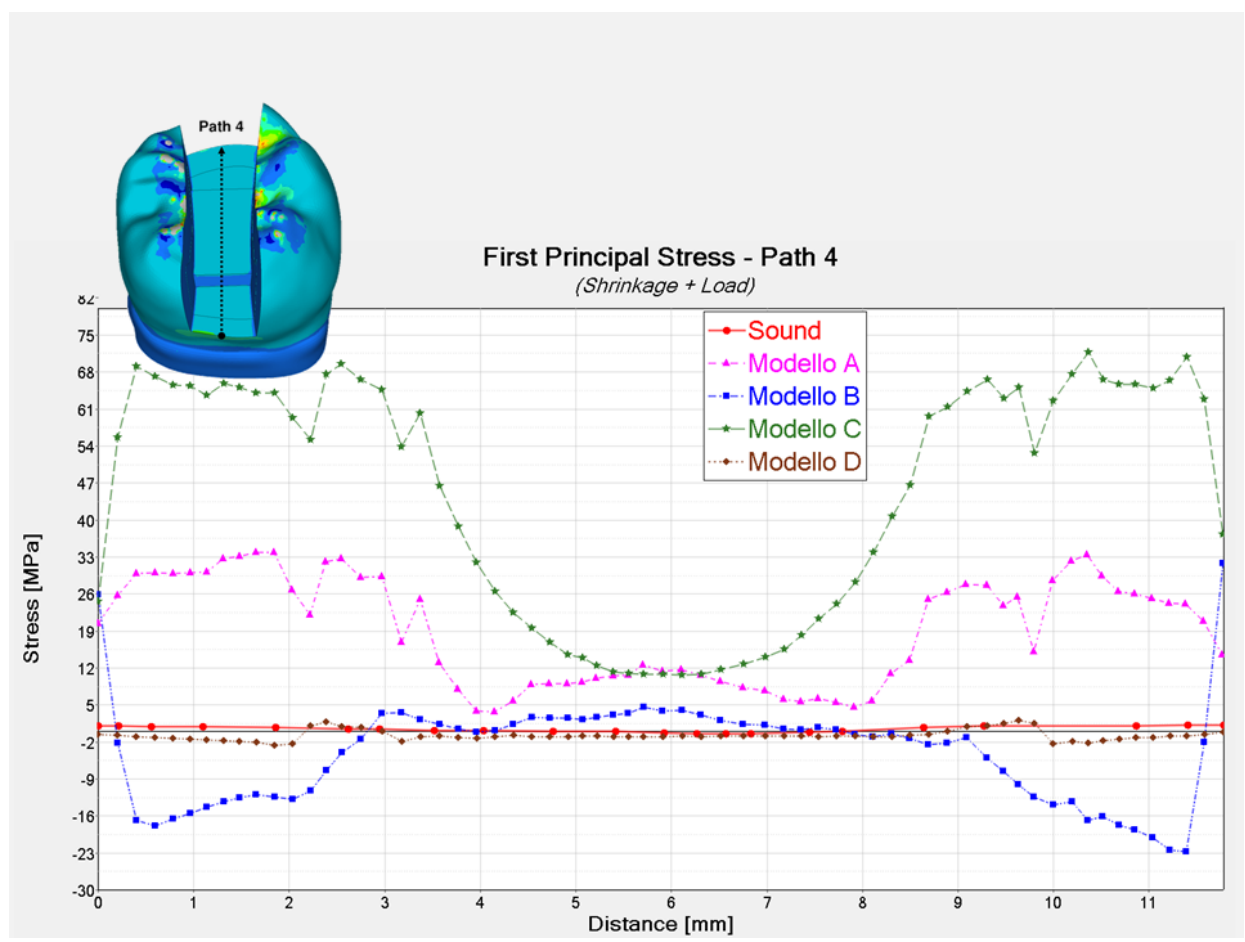

Figure 8 - First principal stress distributions (MPa) along inspection path 4

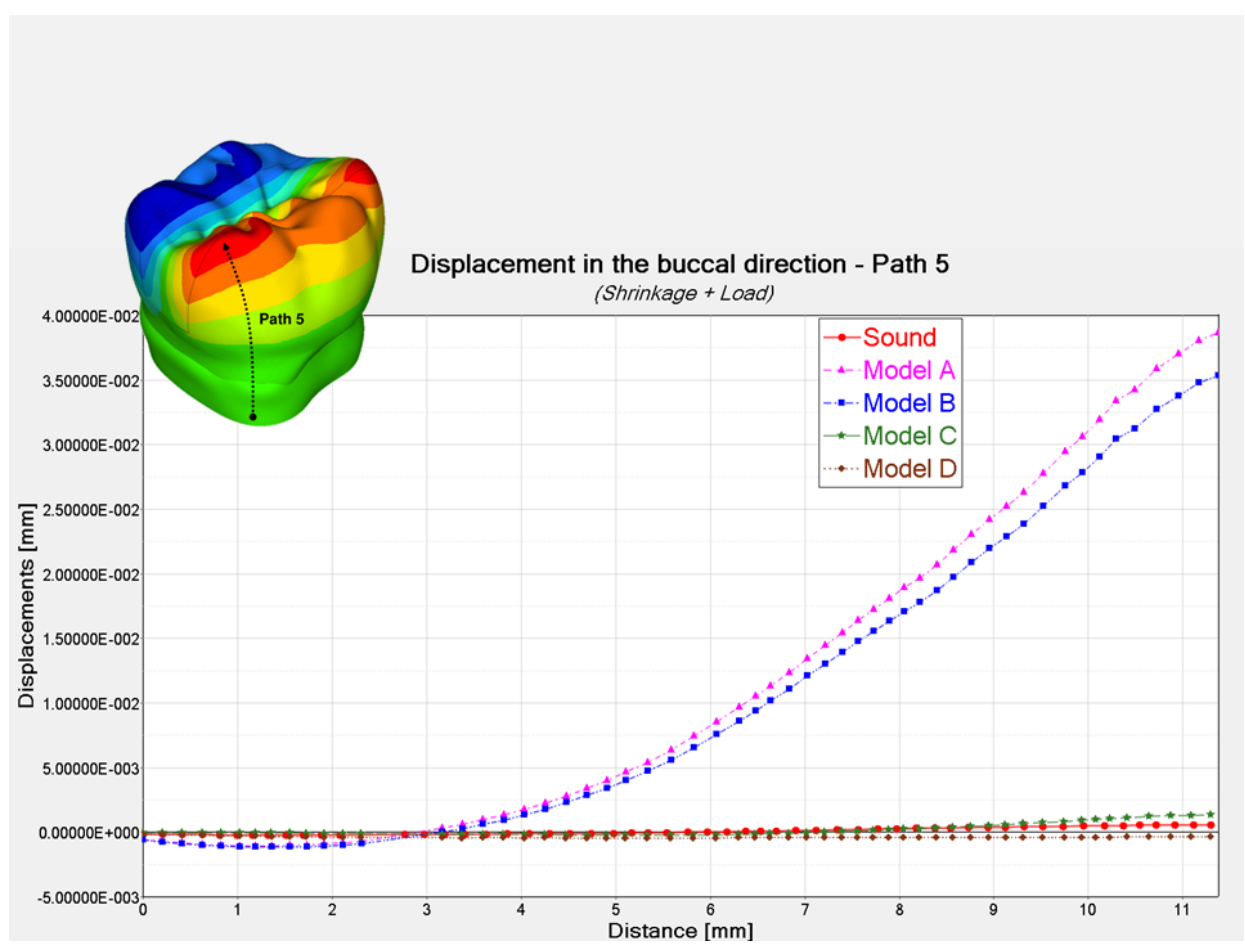

Figure 9 - Displacements in the buccal direction $(\mathrm{mm})$ along inspection path 5

\section{Tables captions}

Table 1 - Mechanical properties of materials: Young's moduli, Poisson's ratio and linear shrinkage $[16,17,24-26]$. 


\begin{tabular}{ccccccc}
\hline Model & Type & $\begin{array}{c}\text { Maximum } \\
\text { aspect ratio }\end{array}$ & $\begin{array}{c}\text { Total \# of } \\
\text { Grids }\end{array}$ & $\begin{array}{c}\text { Total \# of } \\
\text { Elements }\end{array}$ & $\begin{array}{c}\text { Total \# of } \\
\text { Contact } \\
\text { Elements }\end{array}$ & $\begin{array}{c}\text { Total \# of } \\
\text { Degrees of } \\
\text { Freedom }\end{array}$ \\
\hline S & sound & 2.67 & 54281 & 287351 & 9733 & 185712 \\
$\begin{array}{c}\text { A, B, C } \\
\text { and D }\end{array}$ & restored & 2.51 & 67419 & 228857 & 12296 & 243870 \\
\hline
\end{tabular}

Table 2 - Analyzed FEM models 


\begin{tabular}{llcc}
\hline \multicolumn{1}{c}{ Material } & $\begin{array}{c}\text { Young's modulus } \\
\text { (GPa) }\end{array}$ & $\begin{array}{c}\text { Poisson's } \\
\text { ratio }\end{array}$ & $\begin{array}{c}\text { Linear } \\
\text { Shrinkage } \\
(\%)\end{array}$ \\
\hline Dentin & 18 & 0.23 & -- \\
\hline Enamel & 80 & 0.30 & -- \\
\hline Food bolus & 0.01 & 0.30 & 1.0 \\
\hline Resin bonding layer & 4 & 0.30 & 1.0 \\
\hline Flowable resin composite as dentin replacing material & 8 & 0.25 & 1.0 \\
\hline $\begin{array}{l}\text { Direct resin filling composite as enamel replacing } \\
\text { material }\end{array}$ & 12 & 0.25 & -- \\
\hline GIC as dentin replacing material & & 0.25 & 1.0 \\
\hline Luting resin cement & 8 & 0.30 & -- \\
\hline Lithium disilicate machinable inlay & 6 & 0.25 & \\
\hline
\end{tabular}

